\title{
STUDI PHARMACOVIGILANCE OBAT HERBAL DI PUSKESMAS KASIHAN II BANTUL
}

\section{PHARMACOVIGILANCE STUDY OF HERBAL MEDICINE IN PUBLIC HEALTH CENTER OF KASIHAN II BANTUL}

\author{
Nur Mahdi ${ }^{1)}$, Dyah Aryani Perwitasari ${ }^{2)}$, Nyoman Kertia ${ }^{3)}$ \\ ${ }^{1)}$ Fakultas Farmasi Universitas Muhammadiyah Banjarmasin \\ ${ }^{2)}$ Fakultas Farmasi Universitas Ahmad Dahlan \\ ${ }^{3)}$ Fakultas Kedokteran Universitas Gajah Mada \\ Email: nurmahdi.farm@gmail.com
}

\begin{abstract}
ABSTRAK
Kejadian Reaksi Obat yang Tidak Dikehendaki (ROTD) dari obat-obat herbal merupakan hal yang masih jarang diteliti di Indonesia. Gaya hidup kembali ke alam menjadi cukup popular saat ini, sehingga masyarakat kembali memanfaatkan berbagai bahan alam, termasuk pengobatan dengan tumbuhan obat atau herbal. Dengan meningkatnya penggunaan obat herbal di Indonesia, maka diperlukan pemantauan keamanan pada obat-obat herbal. Tujuan penelitian ini adalah mengetahui gambaran kausalitas kejadian ROTD serta mengetahui kualitas hidup pasien yang mendapatkan resep obat herbal. Penelitian ini menggunakan rancangan observasional deskriptif, pengambilan data secara consecutive sampling secara prospektif. Pengambilan data selama dua bulan saat penelitian berlangsung, setelah itu dianalisis kejadian ROTD dan tanpa ROTD serta dinilai kualitas hidup pasien. Instrumen yang digunakan untuk menganalisis adalah algoritma Naranjo dan kuesioner SF-36. Hasil wawancara kepada 25 subyek penelitian pada pengamatan prospektif dan retrospektif, subyek yang melaporkan adanya kejadian ROTD sebanyak 3 subyek (12\%). Sebanyak 2 subyek dengan kategori possible (mungkin) dan 1 subyek dengan kategori probable (cukup mungkin). ROTD yang muncul adalah gatal-gatal, nyeri pinggang, mual, ngantuk dan dada berdebar. Kesimpulan dari penelitian ini adalah terdapat kejadian ROTD pada pasien yang diberikan terapi herbal, gambaran kausalitas kejadian ROTD adalah kategori possible dan probable.
\end{abstract}

Kata kunci: pharmacovigilance, reaksi obat yang tidak dikehendaki, obat herbal. 


\begin{abstract}
Adverse Drug Reactions of herbal medicines is still rarely investigated in Indonesia. Lifestyle of back to nature became quite popular today, so that people re-use a variety of natural materials, including treatment with medicinal plants or herbs. By the increasing use of herbal medicines in Indonesia, it is necessary to monitor safety in herbal medicines. Objectiveof this study To understand the description of ADRs causality and the quality of life of patients who receive a prescription of herbal medicine.This was observational descriptive study, making consecutive sampling data in the prospectively. Data was collected for two months. The incidence of $A D R$, the causality and patients quality of life who assessed. The instrument used to analyze the Naranjo algorithm and the SF-36 questionnaire.The results of interviews with 25 study subjects, subjects who reported a similar incidence of ADRs many as 3 subjects (12\%). Around 2 subjects with possible category and 1 subject in the probable category. ADRs that appear were pruritus, back pain, nausea, sleepiness and tachycardia. We concluded there are ADRs in patients given herbal therapies, the incidence of ADRs overview of causality is possible and probable category.
\end{abstract}

Keywords: pharmacovigilance, adverse drug reactions, herbal medicine.

\title{
PENDAHULUAN
}

Peningkatan penggunaan produk herbal dan obat herbal secara global menyebabkan anggapan masyarakat tentang obat herbal selalu aman dan tidak membahayakan karena berasal dari tumbuh-tumbuhan. Namun, ada kekhawatiran menimbulkan efek samping dari tanaman obat tersebut. Meningkatnya penggunaan obat herbal, maka diperlukan pemantauan keamanan pada obat-obat herbal (Awodele et al, 2013).

Penggunaan obat-obat herbal dan tradisional menimbulkan kekhawatiran terkait keamanannya. Ada kekeliruan persepsi pemahaman alami berarti aman. Ada juga tradisi kepercayaan secara umum bahwa penggunaan obat herbal dalam jangka panjang akan menjamin khasiat dan keamanannya. Contoh obat tradisional dan herbal yang dicampur atau dikombinasi dengan obat-obat allopathic (konvensional), seperti kortikosteroid, golongan antiinflamasi non-steroid dan logam berat (WHO, 2002).

Obat tradisional telah banyak diproduksi secara global dan penggunaannya bergeser keluar dari lingkup budaya dan tradisional sebagaimana pada awal 
dimaksudkan. Pengobatan ini sendiri lebih membahayakan bagi pasien, ketika obat-obat tradisional dan herbal digunakan bersama dengan obat lain menimbulkan potensi interaksi obat yang serius dan merugikan (WHO, 2002).

Penggunaan obat-obatan herbal oleh jutaan orang sejak zaman prasejarah merupakan aspek yang ditekankan oleh para herbalis. Hal ini disimpulkan bahwa obat-obat herbal bebas dari efek samping, karena obat herbal tidak efektif seperti obat-obat konvensional. Tidak adanya informasi yang serius tentang efek samping dan toksisitas obat herbal, maka sulit untuk memberikan jawaban yang memuaskan untuk perbedaan tersebut (Capasso et al, 2003).

Penelitian yang dilakukan Tesch (2002) dengan randomized controlled trials di Amerika Serikat, memaparkan bahwa penggunaan herbal seperti Ginkgo biloba memperlambat perkembangan demensia dengan efek samping meningkatkan risiko perdarahan. Ginseng meningkatkan perbaikan pada wanita premenopause, namun biasanya memiliki efek samping serta interaksi obat. Bawang putih menurunkan sedikit tekanan darah dan kolesterol. Echinacea sedikit mengurangi durasi pilek tetapi tidak menghilangkan durasi pilek secara langsung (Tesch, 2002).

Penentuan atau penegakan hubungan kausal antara kejadian ROTD yang terjadi atau teramati dengan penggunaan obat oleh pasien dilakukan evaluasi dengan analisis kausalitas. Tersedia beberapa algoritma atau tool untuk melakukan analisis kausalitas terkait ROTD. Pendekatan yang dilakukan pada umumnya adalah kualitatif sebagaimana kategori kausalitas yang dikembangkan oleh World Health Organization (WHO), dan juga gabungan kualitatif dan kuantitatif seperti Algoritma Naranjo (Anonim, 2012).

Penelitian ini bertujuan untuk mengetahui kejadian dan gambaran kausalitas ROTD pada pasien yang diberikan resep obat herbal serta menilai kualitas hidup pasien yang mendapat resep obat herbal di Puskesmas Kasihan II Bantul. 


\section{METODOLOGI PENELITIAN}

Penelitian ini menggunakan desain penelitian observasional deskriptif, pengambilan data secara prospektif pada pasien yang menerima obat herbal di Puskesmas Kasihan II Bantul. Populasi yang menjadi target pada penelitian ini adalah pasien yang mendapatkan resep obat herbal di Puskesmas Kasihan II Bantul. Populasi terjangkau adalah pasien yang mendapatkan resep obat herbal di Puskesmas Kasihan II Bantul periode Oktober-Desember 2015. Sampel penelitian adalah semua populasi terjangkau yang memenuhi kriteria inklusi dan eksklusi.

Kriteria Inklusi pada pengamatan prospektif yaitu: 1). pasien laki-laki atau perempuan yang mendapat resep obat herbal berumur 18-85 tahun 2). pasien yang mendapat resep obat herbal yang sedang berobat di Puskesmas Kasihan II Bantul selama periode Oktober-Desember 2015 3). bersedia ikut dalam penelitian ini. Kriteria Eksklusi yaitu: 1). pasien laki-laki atau perempuan yang mendapat resep obat herbal berumur 18-85 tahun 2). memiliki gangguan fungsi kognitif 3). pasien menolak/ hilang untuk ditindaklanjuti 4). pasien tidak jelas mengisi formulir data pasien. Teknik pengambilan sampel dalam penelitian ini adalah non probability consecutive sampling. Instrumen penelitian berupa lembar wawancara ROTD yang diadopsi dari algoritma Naranjo.

Penentuan hubungan kausal antara kejadian efek samping yang terjadi atau teramati dengan penggunaan obat oleh pasien, dilakukan evaluasi dengan analisis kausalitas secara kualitatif dan kuantitatif dengan algoritma Naranjo. Pernyataan subyek penelitian dari hasil wawancara terpimpin kemudian dilakukan scoring berdasarkan ketentuan algoritma Naranjo sebagai berikut pada Tabel I. 
Tabel I. Algoritma Naranjo

\begin{tabular}{|c|c|c|c|c|c|}
\hline No. & Pertanyaan & Ya & Tidak & $\begin{array}{l}\text { Tidak } \\
\text { Tahu }\end{array}$ & Skor \\
\hline 1 & $\begin{array}{l}\text { Apakah ada laporan penelitian sebelumnya tentang reaksi } \\
\text { ini? }\end{array}$ & +1 & 0 & 0 & \\
\hline 2 & $\begin{array}{l}\text { Apakah reaksi muncul setelah obat yang dicurigai } \\
\text { diberikan? }\end{array}$ & +2 & -1 & 0 & \\
\hline 3 & $\begin{array}{l}\text { Apakah reaksi ini berkurang saat obat dihentikan atau } \\
\text { antagonis obat yang spesifik diberikan? }\end{array}$ & +1 & 0 & 0 & \\
\hline 4 & $\begin{array}{l}\text { Apakah reaksi muncul kembali saat obat digunakan } \\
\text { kembali? }\end{array}$ & +2 & -1 & 0 & \\
\hline 5 & $\begin{array}{l}\text { Apakah ada penyebab alternatif (selain obat) yang dapat } \\
\text { menyebabkan reaksi ini? }\end{array}$ & -1 & +1 & 0 & \\
\hline 6 & Apakah reaksi muncul kembali saat diberikan placebo? & -1 & +2 & 0 & \\
\hline 7 & $\begin{array}{l}\text { Apakah obat terdeteksi dalam darah (atau cairan lain) dalam } \\
\text { konsentrasi yang diketahui toksik? }\end{array}$ & +1 & 0 & 0 & \\
\hline 8 & $\begin{array}{l}\text { Apakah reaksi lebih berat saat dosis dinaikkan, atau } \\
\text { berkurang saat dosis diturunkan? }\end{array}$ & +1 & 0 & 0 & \\
\hline 9 & $\begin{array}{l}\text { Apakah pasien mempunyai reaksi yang mirip pada obat } \\
\text { yang sama atau mirip pada pemaparan sebelumnya? }\end{array}$ & +1 & 0 & 0 & \\
\hline 10 & Apakah reaksi dikonfirmasi dengan suatu bukti obyektif? & +1 & 0 & 0 & \\
\hline \multicolumn{6}{|c|}{\begin{tabular}{|l} 
Total Skor \\
\end{tabular}} \\
\hline
\end{tabular}

Hasil scoring menjadi dasar penentuan kategori ROTD sebagai berikut:

- >9 : Sangat Mungkin/ Highly probable

- 5-8 : Mungkin/ Probable

- 1 - 4 : Cukup mungkin/ Possible

- 0 : Ragu-ragu/ Doubtful (Naranjo et al, 1981).

Analisis data disajikan secara deskriptif, hasil yang diharapkan dari penelitian ini adalah proporsi kejadian ROTD dan tidak ada ROTD yang didapat pasien dari peresepan obat herbal. Penentuan hubungan kausal antara kejadian efek samping yang terjadi atau teramati dengan penggunaan obat oleh pasien, dilakukan evaluasi dengan analisis kausalitas secara kualitatif dengan algoritma Naranjo.

\section{HASIL DAN PEMBAHASAN}

Penelusuran data dilakukan selama bulan Oktober sampai Desember 2015 di Puskesmas Kasihan II Bantul. Penetapan subyek penelitian diawali dengan pemilihan kriteria pasien yang mendapatkan resep obat herbal di Puskesmas 
Kasihan II Bantul berdasarkan kriteria inklusi yang telah ditetapkan pada prospektif.

Sebanyak 25 subyek penelitian yang memenuhi kriteria inklusi pada pengamatan prospektif dari bulan Oktober-Desember 2015. Kriteria yang memenuhi inklusi ada 26 subyek, 1 subyek dikeluarkan karena subjek tidak berada di rumah saat peneliti melakukan kunjungan beberapa kali, sehingga hanya 25 subjek yang memenuhi kriteria inklusi.

Distribusi Karakteristik Subyek Penelitian

Karakteristik demografi pasien dapat dilihat pada Tabel II.

Tabel II. Distribusi demografi subyek yang mendapat obat herbal di Puskesmas Kasihan II Bantul bulan Oktober sampai Desember $(n=25)$

\begin{tabular}{lc}
\hline \multicolumn{1}{c}{ Karakteristik } & Total (n (\%)) \\
\hline Umur & $6(24 \%)$ \\
-18-51 Tahun & $19(76 \%)$ \\
-52-85 Tahun & \\
& \\
Jenis Kelamin & $8(32 \%)$ \\
-Laki-laki & $17(68 \%)$ \\
-Perempuan & \\
Status Pekerjaan & \\
-Tidak Bekerja & $11(44 \%)$ \\
-Bekerja & $14(56 \%)$ \\
Status Pendidikan & \\
-SD/ Tidak Sekolah & $16(64 \%)$ \\
-SMP/SMA & $8(32 \%)$ \\
-DIII & $1(4 \%)$ \\
Status Penghasilan & \\
-Tidak Berpenghasilan & $12(48 \%)$ \\
-Berpenghasilan & $13(52 \%)$ \\
\hline
\end{tabular}

Tabel II menunjukkan bahwa karakteristik umur yang dominan pada umur 18-51 tahun sebanyak 6 orang (24\%). Hasil distribusi pada karakteristik jenis kelamin, proporsi laki-laki sebanyak 8 orang (32\%) dan perempuan sebanyak 17 orang (68\%). Pada status pekerjaan, proporsi yang bekerja sebanyak 14 (56\%), dan yang tidak bekerja 11 orang (44\%). Pada pengamatan prospektif menunjukkan bahwa umur $>52$ tahun telah mengalami penurunan kesehatan 
dibandingkan dengan umur $<52$ tahun dan proporsi jenis kelamin perempuan lebih banyak berobat daripada laki-laki. Hal ini menunjukkan perubahan kualitas hidup perempuan lebih rendah yang menyebabkan penurunan kesehatan mental dari laki-laki (Johansen et al, 2016).

Pada karakteristik tingkat pendidikan didapatkan kategori tingkat DIII sebanyak 1 orang (4\%), jenjang SMP sampai SMA sebanyak orang 8 orang (32\%), dan yang tidak bersekolah sampai SD sebanyak 16 orang (64\%). Pada karakteristik status penghasilan, sebanyak 13 orang yang berpenghasilan (52\%), dan yang tidak berpenghasilan 12 orang (48\%). Merujuk kepustakaan bahwa pasien dengan berpenghasilan kecil di negara Hongkong lebih banyak yang berobat dengan herbal medicines dibanding dengan berpenghasilan menengah sampai tinggi (Wong et al, 2011).

Persentase Peresepan Obat Herbal

Distribusi profil peresepan obat herbal meliputi merek obat herbal serta komposisi tanaman yang diresepkan kepada 25 subyek penelitian ditunjukkan pada Tabel III.

Tabel III. Persentase Peresepan obat herbal pada pasien yang mendapat obat herbal di Puskesmas Kasihan II Bantul ( $\mathrm{n}=25)$

\begin{tabular}{lll}
\hline Nama Obat & Kandungan & Total (\%) \\
\hline Tensigard & Apii herba extractum & $14(56 \%)$ \\
& Orthosiphonis folium extractum & $7(28 \%)$ \\
Niran & Phylanthi herba extractum & $1(4 \%)$ \\
Calcusol & Sonchi folium extractum & $1(4 \%)$ \\
Vegeta & Plantaginis ovatae semen pulveratum & \\
Vegeta Herbal & Sennae folium extractum & \\
& Rhei radix extractum siccum & $1(4 \%)$ \\
& Foeniculi fructus dry extractum & \\
& Liquirittiae extractum siccum & \\
& Plantaginis ovatae semen pulveratum & \\
Diapet & Psidii folium extractum & $1(4 \%)$ \\
& Curcuma domisticae rhizoma & \\
& Teminalia chebulae fructus & \\
& Granati pericarpium & \\
\hline
\end{tabular}

Sebanyak 14 subyek yang mendapatkan fitofarmaka Tensigard, persentase peresepan Tensigard paling sering dibanding obat herbal lainnya. Hal ini 
dikarenakan banyaknya pasien lansia yang menderita hipertensi baik yang disertai komplikasi maupun yang tidak dengan komplikasi, yang berobat di puskesmas Kasihan II Bantul.

Tensigard merupakan fitofarmaka yang mempunyai komposisi dari daun kumis kucing dan daun seledri, keduanya memiliki aktivitas seperti diuretik. Menurut Supari (2002) penelitiannya Lowering Blood Plessure Effect of Apium graviolens and Orthosiphon stamineus benth in mild and moderate hypertension memaparkan bahwa seledri (Apium graviolens) banyak mengandung senyawa flavonoid yaitu apigenin yang memiliki aktivitas biologis seperti Calcium antagonist dan manitol yang berfungsi sebagai diuretik. Daun kumis kucing (Orthosiphonis stamineus) mengandung senyawa bioaktif methylripariochromene A yang memiliki aktivitas biologis vasodilator, menurunkan cardiac output dan efek diuretik.

Herba meniran (Phyllanthi Herba) merupakan kandungan dari obat herbal Niran. Herba meniran secara tradisional digunakan untuk antihepatitis. Herba meniran mengandung senyawa filantin, hipofilantin, filantenol, nirantin, nirurin, kuersetin, rutin, asam galat, isokuersetin, dan asam lemak. Filantin dan hipofilantin diduga merupakan senyawa yang berkhasiat sebagai hepatoprotektor, karena itu filantin dijadikan marker pada sediaan yang mengandung meniran. Selain itu senyawa yang terkandung dalam meniran dilaporkan memiliki aktivitas antiinflamasi dan antioksidan yang kuat. Penelitian lain melaporkan senyawa yang diisolasi dari tanaman ini sangat berguna untuk meningkatkan imunitas (Mun'im and Hanani, 2011).

Daun tempuyung (Sonchi folium) merupakan komposisi dari obat herbal Calcusol. Aktivitas dari daun tempuyung belum banyak dilaporkan. Pada satu penelitian dilaporkan bahwa pemberian ekstrak etanolik daun tempuyung 300 $\mathrm{mg} / \mathrm{kg}$ BB memperlihatkan efek diuresis lebih kuat dibandingkan dengan pemberian furosemid pada dosis $0,72 \mathrm{mg} / \mathrm{kg}$ BB. Kadar natrium darah lebih rendah, sedangkan kalium darah lebih tinggi dibandingkan pada pemberian furosemid (Mun'im and Hanani, 2011). 
Profil Kejadian ROTD

Subyek yang melaporkan adanya kejadian ROTD sebanyak 3 orang (12\%) ditunjukkan pada Tabel IV dan Tabel V.

Tabel IV. Persentase kejadian ROTD pada subyek yang mendapat obat herbal di Puskesmas Kasihan II Bantul bulan Oktober sampai Desember

\begin{tabular}{|c|c|c|}
\hline Kategori & (n) & $\%$ \\
\hline Ada ROTD & 3 & 12 \\
\hline Tidak ada ROTD & 22 & 88 \\
\hline Total & 25 & 100 \\
\hline
\end{tabular}

Tabel V. Profil kejadian ROTD pada subyek penelitian di Puskesmas Kasihan II Bantul bulan Oktober dan Desember $(n=25)$

\begin{tabular}{cccccc}
\hline \multirow{2}{*}{ Subyek } & Terapi & \multicolumn{3}{c}{ Kejadian ROTD } & Obat yang \\
\cline { 3 - 5 } diduga
\end{tabular}

Tabel IV menunjukkan sebanyak 3 subyek penelitian pengamatan prospektif melaporkan telah mengalami kejadian ROTD dengan penggunaan Tensigard dan Niran, sebanyak 2 subyek dengan kategori possible (mungkin) dan 1 subyek dengan kategori probable (cukup mungkin). Supari (2002) melaporkan adanya efek samping dari kedua tanaman dari obat herbal tersebut (kumis kucing dan seledri), meliputi pusing, lemah, kemerahan pada wajah, mual, ngantuk dan takikardi.

ROTD yang dialami subyek penelitian meliputi gatal-gatal dan dada berdebar. Sebanyak 3 subyek diwawancara dengan tool yang merujuk pada algoritma Naranjo mengenai kejadian dugaan ROTD tersebut. Gatal yang dialami bersifat ringan dan setelah berhenti mengonsumsi Tensigard, gatal tersebut hilang. Peneliti mengasumsikan bahwa kejadian ROTD tersebut setelah dikorelasikan dengan algoritma Naranjo merupakan kategori probable dan possible. Efek samping atau kejadian ROTD dari family Apiaceae lainnya termasuk dermatitis 
kontak alergi setelah penggunaan topikal, keluhan lambung dan mual juga dilaporkan setelah pemberian oral (Capasso et al, 2003). Efek samping atau kejadian ROTD dari family Lamiaceae lainnya termasuk gangguan pencernaan serta retensi garam dan air (Venkateshappa and Sreenath, 2013).

\section{KESIMPULAN}

Dari 25 subyek penelitian yang diberikan terapi obat herbal pada pengamatan prospektif, sejumlah 3 subyek (12\%) yang melaporkan adanya kejadian ROTD. Dari 25 subyek penelitian yang diberikan terapi obat herbal pada pengamatan retrospektif sejumlah 7 subyek (28\%) yang melaporkan adanya kejadian ROTD. Gambaran kausalitas pada kejadian ROTD sebanyak 2 subyek dengan kategori possible dan 5 subyek dengan kategori probable pada pengamatan retrospektif. Gambaran kausalitas pada kejadian ROTD sebanyak 2 subyek dengan kategori possible dan 1 subyek dengan kategori probable pada pengamatan prospektif.

\section{UCAPAN TERIMAKASIH}

Kepada Kepala Puskesmas Kasihan II Bantul beserta staf yang telah memberikan izin untuk melakukan penelitian di Puskesmas Kasihan II Bantul, serta seluruh pihak yang telah memberikan kontribusi dalam penulisan karya ilmiah ini.

\section{DAFTAR PUSTAKA}

Anonim, 2012, Pedoman Monitoring Efek Samping Obat Bagi Tenaga Kesehatan, Badan POM RI, Jakarta.

Aronson, J. (Ed.), 2009, Meyler's Side Effects of Herbal Medicines, Elsevier.

Awodele, O., Daniel, A., Popoola, T. D., \& Salami, E. F., 2013, A Study on Pharmacovigilance of Herbal Medicines in Lagos West Senatorial District, Nigeria. International Journal of Risk and Safety in Medicine, 25 (4) : 205217. 
Capasso, F., Gaginella, T. S., Gransdolini, G., \& Izzo, A. A., 2003, Phytotherapy A Quick Reference to Herbal Medicine, Springer, New York, http://doi.org/10.1007/978-3-662-04482-7

Cicero, A. F. ., Derosa, G., Brillante, R., Bernardi, R., Nascetti, S., \& Gaddi, A., 2004, Effects of Siberian Ginseng (Eleutherococcus senticosus maxim.) on Elderly Quality of Life: A Randomized Clinical Trial, Archives of Gerontology and Geriatrics Supplement, 9 : 69-73, http://doi.org/10.1016/j.archger.2004.04.012

Mun'im, A., \& Hanani, E., 2011, Fitoterapi Dasar. Dian Rakyat, Jakarta.

Naranjo, C. A., Busto, U., Sellers, E. M., Sandor, P., Ruiz, I., Roberts, E. A., ... Greenblatt, D. J., 1981, A Method for Estimating The Probability of Adverse Drug Reactions. Clinical Pharmacology and Therapeutics, 30 (2) : 239-245. http://doi.org/10.1038/clpt.1981.154

Purshel, J., 2015, The Herbal Apothecary: 100 Medicinal Herbs and How to Use Them. Portland, Oregon: Library of Congress Cataloging-in-Publication Data.

Reich, A., Ständer, S., \& Szepietowski, J. C., 2009, Drug-induced pruritus: A review, Acta Dermato-Venereologica, 89 (3) : 236-244. http://doi.org/10.2340/00015555-0650

Supari, F., 2002, Lowering Blood Pressure Effect of Apium graviolens (Seledri) and Orthosipleon stamineus benth (Kumis Kucing) in Mild and Moderate Hypertension, I (4) : 2-8.

Tesch, BJ, 2002, "Herbs Commonly Used by Women: An Evidence-Based Review." Disease a month : DM, http://www.ncbi.nlm.nih.gov/pubmed/12562054.

Venkateshappa, S., \& Sreenath, K., 2013, Potential Medicinal Plants of Lamiaceae, American International Journal of Research in Formal, Applied \& Natural Sciences, 3 (1) : 82-87.

WHO, 2002, Safety Monitoring of Medicinal Products; The Importance of Pharmacovigilance, Geneva.

Wong, W., Lam, L. K. C., Li, R., Ho, S. H., Fai, L. K., \& Li, Z., 2011, A Comparison of The Effectiveness Between Western Medicine and Chinese Medicine Outpatient Consultations in Primary Care, Complementary Therapies in Medicine, 19 (5) : 264-275, http://doi.org/10.1016/j.ctim.2011.07.001 
Wong, W., Lo, C., Lam, K., Wong, V. T., Yang, Z. M., Ziea, E. T., Kwan, L., 2013, Validation of The Constitution in Chinese Medicine Questionnaire : Does The Traditional Chinese Medicine Concept of Body Constitution Exist? EvidenceBased Complementary and Alternative Medicine, http://doi.org/http://dx.doi.org/10.1155/2013. 